\title{
Magnetic, magnetocaloric and thermoelectric properties of Nickel doped manganites
}

\author{
Abd El-Moez A. Mohamed ${ }^{* a, b}$, B. Hernando ${ }^{\mathrm{b}}$, A. M. Ahmed ${ }^{\mathrm{a}}$ \\ ${ }^{a}$ Physics Department, Faculty of Science, Sohag University, Sohag, 82524, Egypt \\ ${ }^{\mathrm{b}}$ Physics Department, Faculty of Science, Oviedo University, Oviedo, 33007, Spain
}

\begin{abstract}
\end{abstract}
In this study, we investigate structural, magnetic, magnetocaloric and thermoelectric properties of $\mathrm{La}_{0.7} \mathrm{Sr}_{0.3} \mathrm{Mn}_{1-\mathrm{x}} \mathrm{Ni}_{\mathrm{x}} \mathrm{O}_{3}$ compounds with $0.025 \leq \mathrm{x} \leq 0.125$. X-ray diffraction analysis shows the structure transformation from the R-3c rhombohedral to the Pbnm orthorhombic structure with $\mathrm{Ni}^{2+}$ doping at $\mathrm{x} \geq 0.075$ composites. The $\mathrm{dc}$ thermal magnetization measurements reveal the monotonic decrease in both Curie temperature and magnetization values with $\mathrm{Ni}^{2+}$ addition. The change in magnetic properties of the studied system is correlated to the ferromagnetism suppression and the antiferromagnetism promotion according to some cooperative intrinsic and extrinsic factors. Results show that $\mathrm{Ni}^{2+}$ doping affects the magnetocaloric properties, where it shifts the maximum value of the magnetic entropy change towards lower temperatures with relative cooling power of $88,105,47 \mathrm{~J} / \mathrm{kg}$ for $\mathrm{x}=0.025,0.075$ and 0.125 composites, respectively. Moreover, it is observed that $\mathrm{Ni}^{2+}$ doping increases the absolute value of Seebeck coefficient and decreases hole conduction interval,

Key Words: Crystal structure; Composite materials; Magnetic properties; entropy; Magnetocaloric effect; Thermoelectric properties.

*Corresponding author: abdmoez_hussien@science.sohag.edu.eg

\section{Introduction}

Pervoskite doped manganites are remarkable materials characterized by various magnetic phenomena as the colossal magnetoresistance (CMR) [1] and the magnetocaloric effect (MCE) [2]. These phenomena have an intrinsic origin occurring around the Curie 
temperatures $\left(\mathrm{T}_{\mathrm{c}}\right)$ and they are governed by the double exchange interaction (DE) between $\mathrm{Mn}^{3+}$ and $\mathrm{Mn}^{4+}$ ions $\left(\mathrm{Mn}^{3+}-\mathrm{O}-\mathrm{Mn}^{4+}\right)$. In spite of the interesting CMR phenomenon, but its magnetic field dependence restrains the practical implementations due to the high magnetic fields used to achieve the high CMR values. This has increased the necessity to the high sensitive magnetoresistive materials for low applied magnetic fields. This kind of MR has been observed in granular manganites [3] and was known as the low field magnetoresistance (LFMR). The LFMR has been attributed to spin scattering and spin polarized tunneling at grain boundaries [3] revealing the LFMR extrinsic origin.

Magnetic refrigeration is an environmental friendly technique working with energy saving of $30 \%$ better than the conventional gas compression refrigerators [4]. This technique depends on the magnetic entropy change $(\Delta S)$ of magnetic material upon magnetic field application/removal. In details, magnetic field application decreases spin entropy through their alignment in the magnetic field direction. Adiabatically, this decrease in spin entropy is compensated by an increase in the lattice entropy that increases $\Delta S$ leading to heat releasing. Due to the interesting physico-chemical properties of manganites oxides as the high magnetization and the chemical stability, they have been paid attention for magnetic refrigeration technology. Several literatures have discussed the potential applicability of these oxides [5], where, they show a high MCE response in comparison with the Gd based alloys [6] as $\mathrm{La}_{0.7} \mathrm{Ca}_{0.3} \mathrm{MnO}_{3}$ that shows $\Delta$ s value of $5.27 \mathrm{~J} / \mathrm{kg} . \mathrm{K}$ [7].

Inspite of the outstanding manganites phenomena, but, these phenomena are based on complicated mechanisms. The thermoelectric power measurements of these oxides may help to understand these complicated mechanisms. Where, the systematic analysis of thermoelectric data provides information about the change in band structure and enables us to understand conduction mechanisms. In addition, from the experimental view point, manganites oxides can be considered as good green energy candidates for thermoelectrics 
[8-10]. For example, they can be used in thermoelectric generators by converting the wasted heat from engines to electrical energy.

The partial substitution of Mn-site by other transition metal is an interesting topic that leads to a change in the magnetic coupling between $\mathrm{Mn}^{3+}$ and $\mathrm{Mn}^{4+}$ ions [11], sometimes leads to a structural transition [12] and has the advantage of charge ordering suppression in some manganites [13]. The partial substitution of $\mathrm{Mn}$ by $\mathrm{Ni}$ ions was studied before and the system showed prominent magnetoresistive results [14, 15]. So, in this work, we are trying to understand the magnetic behavior of $\mathrm{La}_{0.7} \mathrm{Sr}_{0.3} \mathrm{Mn}_{1-\mathrm{x}} \mathrm{Ni}_{\mathrm{x}} \mathrm{O}_{3}$ system.

\section{Experimental}

Polycrystalline $\mathrm{La}_{0.7} \mathrm{Sr}_{0.3} \mathrm{Mn}_{1-\mathrm{x}} \mathrm{Ni}_{\mathrm{x}} \mathrm{O}_{3}(\mathrm{LSMN})$ ceramic samples with $0.025 \leq \mathrm{x} \leq 0.125$ were prepared by the solid state reaction method as reported elsewhere [16]. The crystal structure was examined using $\mathrm{x}$-ray diffraction (XRD) technique and the microstructure was investigated by scanning electron microscope (SEM) using a deposited gold layer (Au) on samples surface during imaging process. Magnetic measurements were performed using vibrating sample magnetometer (VSM), and the thermoelectric power measurements were measured by a home built set up.

\section{Results and discussion}

\subsection{Structure}

Room temperature XRD patterns of LSMN composites are shown in Fig.1. The patterns show a single phase of LSMN with additional peaks of $\mathrm{La}_{2} \mathrm{O}_{3}$ phase around $2 \theta=27.5^{\circ}$ that were observed by $[17,18]$. Rietveld refinement of these patterns reveals the $\mathrm{R}-3 \mathrm{c}$ rhombohedral structure for $\mathrm{x} \leq 0.05$ composites and the Pbnm orthorhombic structure for $\mathrm{x} \geq 0.075$ composites, in agreement with Mostafa et al. [19]. The observed structural transformation refers to the disturbance in the $\mathrm{Mn}^{3+} / \mathrm{Mn}^{4+}$ ratio as a result of the $\mathrm{Mn}$-site 
doping that decreases $\mathrm{Mn}^{4+}$ ions, which in turn increases the $\mathrm{Mn}^{3+}$ ratio [20]. It is noteworthy to state that $\mathrm{Mn}^{3+}$ is a Jahn-Teller distortion active ion, so, the observed gradual orthorhombic distortion with increasing $\mathrm{Ni}^{2+}$ content is reasonable. Also, the decrease in the XRD peaks intensity with increasing $\mathrm{Ni}^{2+}$ content suggests the decrease in phase crystallinity. SEM micrographs in Fig. 2 show a distribution of spherical grains, the average grain size decreases with $\mathrm{Ni}^{2+}$ doping and so the XRD crystallite size that was calculated from Laue-Scherrer's equation (see Table 1). Results in Table 1 shows the smaller size of XRD crystallite in comparison with the SEM average grain size. This suggests crystallites clustering inside grains due to structural defects/internal stresses [21]. Fig. 2 also shows the energy dispersive $\mathrm{x}$-ray (EDX) spectra that confirm elements presence through their characteristic peaks as seen in the figure for $\mathrm{x}=0.025$ and $\mathrm{x}=0.075$ as selected samples, in addition to Au peaks that come from the deposited gold layer on the samples surface during the SEM imaging.

\subsection{Magnetic properties and magnetocaloric effect (MCE)}

In this part, we discuss the change in magnetic properties of LSMN system taking into account the intrinsic and the extrinsic factors. The intrinsic factors are represented in a change in magnetic interactions as the ferromagnetic DE interactions $\left(\mathrm{Mn}^{3+}-\mathrm{O}-\mathrm{Mn}^{4+}\right)$ or a change in the internal structure [22], while, the extrinsic factors arise from the change in grain size or the presence of impurity phases [23].

The temperature dependent magnetization curves in Fig. 3 show a paramagneticferromagnetic (PM-FM) transition at the $\mathrm{T}_{\mathrm{c}}$ for all studied composites. The $\mathrm{T}_{\mathrm{c}}$ and the magnetization values decrease monotonically with increasing $\mathrm{Ni}^{2+}$ doping content (see Table 2), which are in agreement with the results of $\mathrm{La}_{0.7} \mathrm{Ca}_{0.3} \mathrm{Mn}_{1-\mathrm{x}} \mathrm{Ni}_{\mathrm{X}} \mathrm{O}_{3}$ [24] and $\mathrm{La}_{0.85} \mathrm{Na}_{0.15} \mathrm{Mn}_{1-\mathrm{x}} \mathrm{Ni}_{\mathrm{x}} \mathrm{O}_{3}$ [25] compounds. Intrinsically, the magnetic properties change arises from the change in magnetic interactions. In other words, the partial substitution of 
$\mathrm{Mn}$ by $\mathrm{Ni}^{2+}$ ions weakens ferromagnetism by decreasing the ferromagnetic DE interactions $\left(\mathrm{Mn}^{3+}-\mathrm{O}-\mathrm{Mn}^{4+}\right)$ forming new antiferromagnetic bonds of $\mathrm{Mn}^{3+}-\mathrm{O}-\mathrm{Ni}^{2+}, \mathrm{Mn}^{4+}-\mathrm{O}-\mathrm{Mn}^{4+}$ and $\mathrm{Ni}^{2+}-\mathrm{O}-\mathrm{Ni}^{2+}$, which are non exchangeable interactions that promote antiferromagnetism. These antiferromagnetic bonds are suggested to increase in number with increasing $\mathrm{Ni}^{2+}$ content due to the continuous decrease in magnetization and $\mathrm{T}_{\mathrm{c}}$ values. Moreover, the structural role in the magnetic properties change can be realized through the increase in Jahn-Teller effect with the gradual orthorhombic distortion, which stabilizes charge ordering in competition with ferromagnetism [26]. With respect to the extrinsic factors role in the magnetic properties change, the decrease in grain size with $\mathrm{Ni}^{2+}$ doping content decreases the grain inner core (the magnetic part) and increases its surface area (the non magnetic layer containing defects) [27], which damps ferromagnetism. Besides, the $\mathrm{La}_{2} \mathrm{O}_{3}$ impurity phase coexistence with the main pervoskite phase leads to a quit broadness in the PM-FM transition in magnetization curves [28-30].

Fig. 4 shows the isothermal magnetization curves for $\mathrm{x}=0.025,0.075$ and 0.125 composites. This figure illustrates the ferromagnetic behavior in curves below $\mathrm{T}_{c}$, where the magnetization increases sharply at the low applied magnetic fields and saturates at the higher values. The figure also shows the paramagnetic behavior above $T_{c}$, where, the magnetization increases linearly with the applied magnetic field. The PM-FM transition nature of these composites can be identified according to the induced Arrott plots in Fig. 4, which are a relation between $M^{2}$ vs $H / M$. According to Banerjee's criteria [31], the positive slope of Arrott plots around $\mathrm{T}_{\mathrm{c}}$ characterizes the second order transition; otherwise, the transition is a first order one. Accordingly, the positive slope of Arrott plots around $\mathrm{T}_{\mathrm{c}}$ reveals the second order transition in our system.

The MCE based on $\triangle \mathrm{S}$ was calculated from the isothermal magnetization curves using the approximated Maxwell equation in Eq.1 [32]. Where, $\mathrm{M}_{i+1}$ and $\mathrm{M}_{i}$ are the 


$$
\begin{aligned}
& \Delta \mathrm{S}(\mathrm{T}, \Delta \mathrm{H})=\sum \frac{M_{i}-M_{i+1}}{T_{i}-T_{i+1}} \Delta H \\
& \mathrm{RCP}=\Delta \mathrm{S}_{\mathrm{Max}} \times \delta \mathrm{T}_{\mathrm{FWHM}}
\end{aligned}
$$

magnetization values measured at $\mathrm{T}_{i+1}$ and $\mathrm{T}_{i}$ temperatures at a magnetic field change $\Delta \mathrm{H}$. The temperature dependent $\Delta \mathrm{S}$ in Fig. 5 shows negative values with a maximum around $\mathrm{T}_{\mathrm{c}}$ $\left(\Delta \mathrm{S}_{\max }\right) . \Delta \mathrm{S}_{\max }$ is shifted towards higher temperature and increases in amplitude with the applied magnetic fields (not shown here). As one can see, $\mathrm{Ni}^{2+}$ doping decreases the $\mathrm{T}_{\mathrm{c}}$ value towards lower temperatures, however, it has a minor effect on the $\Delta S_{\max }$ that shows the values of $0.80,81$ and $0.71 \mathrm{~J} / \mathrm{kg} . \mathrm{K}$ for $\mathrm{x}=0.025,0.075$ and 0.125 composites, respectively. The $\mathrm{Ni}^{2+}$ content independence of $\Delta \mathrm{S}_{\max }$ agrees with Bose et al [33] and can be considered as a merit for magnetic refrigeration applications, because the same material can be used at wide range of temperatures. The $\Delta \mathrm{S}_{\max }$ shift towards lower temperatures refers to the decrease in the $\mathrm{DE}$ interaction with increasing $\mathrm{Ni}^{2+}$ doping, while a possible reason for the insignificant change in the $\Delta S_{\max }$ value may be the magnetic saturation at the used magnetic field value [34]. Results in Table 2 show a change in the $\Delta S(T)$ curve width with $\mathrm{Ni}^{2+}$ doping that can be expressed by the full width at half maximum $\left(\delta \mathrm{T}_{\mathrm{FWHM}}\right)$. The good magnetocaloric material interests with high MCE over a wide range of temperature. So, the MCE efficiency may be expressed interms of the relative cooling power (RCP) in Eq. 2 [34] that depends on both $\Delta \mathrm{S}_{\max }$ and $\delta \mathrm{T}_{\mathrm{FWHM}}$. It refers to the transferred heat between the cold and the hot reservoirs in a refrigerator during one ideal thermodynamic cycle [35]. From the RCP calculations presented in Table 2 we find that $\mathrm{x}=0.025$ composite shows a room temperature MCE of $88 \mathrm{~J} / \mathrm{kg}$ where it shows $\mathrm{T}_{\mathrm{c}}$ value of $310 \mathrm{~K}$, while, $\mathrm{x}=0.075$ composite shows the highest RCP value $(105 \mathrm{~J} / \mathrm{kg}$ ) around $256 \mathrm{~K}$ at $3 \mathrm{~T}$ applied magnetic field.

\subsection{Thermoelectric power (TEP)}


Fig. 6 shows the thermal variation of Seebeck coefficient, S(T), for all composites. Composites with $\mathrm{x} \leq 0.075$ show a crossover from positive to negative $\mathbf{S}$ sign at $T^{*}$, while, $\mathrm{x} \geq 0.1$ composites show a negative $\mathbf{S}$ sign all over the temperature range. This reveals that the conduction in $x \leq 0.075$ composites is due to both electrons and holes, whereas at $x \geq 0.1$ composites, electrons are the only carriers responsible for conduction. $\mathrm{Ni}^{2+}$ doping decreases hole conduction interval until it vanishes at $x \geq 0.1$, this can be inferred by the decrease in $T^{*}$ (see Table 3). The negative $\mathbf{S}$ sign at high temperatures is attributed to the high mobility of electrons in conduction band (CB), which are excited from the valence band (VB). In addition, the non sequential increase in the absolute $\mathbf{S}$ value with $\mathrm{Ni}^{2+}$ doping refers to the decrease in both $\mathrm{DE}$ interaction and $e_{g}$ electron activity [36]. At low temperatures, the VB band electrons are excited into the impurity band generating holelike carriers that is responsible for the positive $\mathbf{S}$ sign [37].

The change of $\mathbf{S}$ sign in the ferromagnetic region suggests a change in the electronic band structure. To explain this change, we will quote Asamitsu et al. model [38]. According to this model, the $\boldsymbol{e}_{\boldsymbol{g}}$ band consists of two orbitals separated by an order of $\boldsymbol{J}_{\boldsymbol{H}}$, and this interaction increases when electrons are excited from VB $\left(t_{2 g}\right)$ to $C B\left(e_{g}\right)$. In degeneracy case, the lower orbital of $\boldsymbol{e}_{g}$ band will be occupied by an electron with a filling probability $\mathrm{n}=1-\mathrm{x}$, in spite of the full filled probability is $\mathrm{n}=2, \mathrm{x}$ is $\mathrm{Sr}^{2+}$ or $\mathrm{Mn}^{4+}$ ratio. $\mathrm{In}$ this case, the lower orbital of $\boldsymbol{e}_{\boldsymbol{g}}$ band is considered as a nearly empty level and the band exhibits a negative $S$ sign according to $S=\pi^{2} k^{2} T / 2 e(d \ln \sigma(E) / d E)$ equation, where conductivity, $\sigma(E)$, is proportional to the number of states, $N(E)$. This equation describes the metallic TEP and indicates that the nearly filled band shows a positive TEP, while the nearly empty band exhibits a negative TEP [39]. By quoting the previous scenario, the negative $\mathbf{S}$ value at $\mathrm{x} \geq 0.1$ suggests the degeneracy of $\boldsymbol{e}_{\boldsymbol{g}}$ band all over the temperature range and its behavior as a nearly empty band showing negative $\mathbf{S}$ values. Whereas at $\mathrm{x} \leq 0.075$ 
composites, the degeneracy of $\boldsymbol{e}_{g}$ band decreases with decreasing temperature that makes it a nearly filled band and behaves as a hole like material, this can be inferred by the change in $\mathbf{S}$ sign.

TEP data were analyzed at low and high temperatures to know the components responsible for behaviors in each region. At high temperatures, the thermal variation of $\mathbf{S}$ obeys Mott equation (Eq. 3) [40], where $e$ is the electronic charge, $k_{B}$ is the Boltzmann constant, $E_{S}$ is the TEP activation energy and $\alpha$ is a constant related to the polaron kinetic energy [41]. Fig. 7 shows the best fitting data with Mott equation at high temperatures for $\mathrm{x}=0.025, \mathrm{x}=0.05$ and $\mathrm{x}=0.125$ composites as selected samples. Table 3 shows the monotonic increases in the $E_{s}$ value with $\mathrm{Ni}^{2+}$ content with a drop at $\mathrm{x}=0.125$ composite, where, the increase in $E_{s}$ is attributed to the increase in carriers scattering with $\mathrm{Ni}^{2+}$ addition.

$$
\begin{gathered}
S=k_{B} / e\left(E_{S} / k_{B} T+\alpha\right) \\
S=S_{0}+S_{3 / 2} T^{3 / 2}+S_{4} T^{4} \\
S_{0}+S_{1} T+S_{3 / 2} T^{3 / 2}+S_{3} T^{3}+S_{4} T^{4}
\end{gathered}
$$

At low temperatures, the ferromagnetic behavior can be explained on the basics of the spin wave theory. According to this theory, charge carriers in ferromagnetic materials are scattered by spin waves increasing the electron-magnon scattering and producing the magnon drag effect. In the same way, electron-phonon interactions can produce the phonon drag effect. So, The TEP data at low temperatures was analyzed by Eq. 4 [42], where $S_{0}$ is a constant, $S_{3 / 2}$ is the magnon drag component and $S_{4}$ is the spin wave fluctuation in the ferromagnetic phase. However, the data shows a worth fitting with this equation, which suggests the contribution of other factors. So, $S$ data was examined again with Eq. 5 [43] and showed a good fitting with this equation that contains two additional components, $S_{I}$ for the diffusion component and $S_{3}$ for the phonon drag component. The fitting parameters 
of Eq. 5 in the ferromagnetic region are displayed in Table 3. As clear from this table, magnon and phonon drag components are nearly small and constant with $\mathrm{Ni}^{2+}$ addition indicating their minor effect on TEP. But, the notable change in diffusion and spin wave fluctuation components shows up their important effect in the TEP below $T_{s}$.

\section{Conclusion}

Structural, magnetic, magnetocaloric and thermoelectric properties of $\mathrm{La}_{0.7} \mathrm{Sr}_{0.3} \mathrm{Mn}_{1-\mathrm{x}} \mathrm{Ni}_{\mathrm{x}} \mathrm{O}_{3}$ composites were studied. Composites show a complete structural transformation from the R-3c rhombohedral to the Pbnm orthorhombic structure at $\mathrm{x} \geq .075$ composites. $\mathrm{T}_{\mathrm{c}}$ and magnetization value decrease with $\mathrm{Ni}^{2+}$ doping due to the decrease in the ferromagnetic DE interactions. $\Delta \mathrm{S}_{\max }$ is shifted towards lower temperature with $\mathrm{Ni}^{2+}$ addition without significant change in the amplitude revealing that these materials can be used in magnetic refrigeration at wide range of temperatures with the same efficiency. In addition, the composites show RCP values of 88,105 and $47 \mathrm{~J} / \mathrm{kg}$ for $\mathrm{x}=0.025, \mathrm{x}=0.075$ and $\mathrm{x}=0.125$ respectively. This nominates $\mathrm{x}=0.075$ to be the best MCE composition among in the studied system, however, $\mathrm{x}=0.025$ composite shows a room temperature magnetocaloric properties. Moreover, the increase in $\mathrm{Ni}^{2+}$ content decreases the hole conduction interval in the TEP measurements and increases the negative $S$ value.

\section{Acknowledgment}

Authors would like to acknowledge the technical support provided by both Sohag and Oviedo universities.

\section{References}

1- J. Hu, Y. Wang, Y. Zhang, H. Liu, H. Qin, L. Bo J. Alloy Compd. 509 (2011) 1360.

2- A. A. Mohamed, V. Vega, M. Ipatov, A.M. Ahmed, B. Hernando, J. Alloys Compd. 657 (2016) 495. 
3- H. Hwang, S. W. Cheong, N. Ong, B. Batlogg, Phys. Rev. Lett. 77 (1996) 2041.

4- N. A. de Olivira, P. J. Von Ranke, Phys. Rep. 489 (2010) 89.

5- A. M. Tishin, Y. I. Spichkin, the magnetocaloric effect and its applications, IOP, 2003.

6- V.K. Pecharsky, K.A. Gschneidner Jr., J. Magn. Magn. Mater 167 (1997) L179.

7- J.C. Debnath, R. Zeng, J.H. Kim, S.X. Dou, J. Appl. Phys. 107 (2010) 09A916.

8- $\quad$ I. Terasaki, Y. Sasago, K. Uchinokura, Phys. Rev. B 56 (1997) R12685.

9- $\quad$ S. Hebert, D. Flahaut, C. Martin, S. Lemonnier, J. Noudem, C. Goupil, A. Maignan, J. Hejtmanek, Prog. Solid State Chem. 35 (2007) 467.

10- V. L. Kozhevnikov, I. A .Leonidov, E. B. Mitberg, M. V. Patrakeev, Y. M. Baikov, V. S. Zakhvalinskii, E. Lahderant, J. Solid State Chem. 172 (2003) 5.

11-L. W. Zhang, G. Feng, H. Liang, B. S. Cao, Z. Meihong, Y. G. Zhao, J. Magn. Magn. Mater. 219 (2000) 236.

12-X. K. Hu, M .H. Xu, Z. S. Wang, S. Y. Zhang, Q. Wu, P. Z. Si, Solid State Commun. 149 (2009) 246.

13- $\quad$ A . Maignan, F. Damay, C. Martin, B. Raveau, Mater. Res. Bull. 32 (1997) 965.

14- S. Liu, Y. Bian, T. Wang, L. Yang, X. Song, J. Zhang, Rev. Adv. Mater. Sci. 33 (2013) 137.

15- A. M. Ahmed, M. A. Abedellateef, H. A. Abd El-Ghanny, and A A. Mohamed, Phys. Status Solidi A 212 (2015) 623.

16- A. M. Ahmed, A. A. Mohamed, M. A. Abdellateef, H. A. Abd El-Ghanny, Rare Met. 35 (2016)551.

17- $\quad$ R. V. Wandekar, B. N. Wani, S. R. Bharadwaj, Solid State Sci. 11 (2009) 250. 
18- $\quad$ R. V. Wandekar, B. N. Wani, S. R. Bharadwaj, Mater. Lett. 59 (2005) 2799.

19- A. G. Mostafa, E. K. Abdel-Khalek, W. M. Daoush, S. F. Moustfa J. Magn. Magn. Mater. 320 (2008) 3356.

20- M. Sugantha, R. S. Singh, A. Guha, A. K. Raychaudhuri, C. N. R. Rao, Mater. Res. Bull. 33 (1998) 1134.

21- C. V. Vazquez, M. C. Blanco, M. A. L. Quintela, R. D. Sanchez, J. Rivas, S. B. Oseroff J. Mater. Chem. 8 (1998) 991.

22- I. A. Serrano, C. Pico, M. L. Veiga, Solid State Sci. 6 (2004) 1321.

23- K. Wang, W. Song, T. Yu, B. Zhao, M. Pu, Y. Sun, Phy. Status Solidi A 171 (1999) 577.

24- G. B. Chon, H. S. Im, M. L. Sang, B. H. Koo, C. G.Lee, M. H. Jung, J. Magn. Magn. Mater. 310 (2007) 927.

25- S.M. Liu, X.B. Zhu, B. Gao, Y.P. Sun, Physica B 387 (2007) 77.

26- C. N. R. Rao, B. Raveau, Colossal magnetoresistance, charge ordering and the related properties of manganese oxides, First ed, World Scientific Pub Co Inc, 1998.

27- P. Dey, T. K. Nath, Phy. Rev. B 73 (2006) 214425.

28- X. J. Liua, Z. Q. Lia, A. Yu, M. L. Liu, W. R. Li, B. L. Li, P. Wu, H. L. Bai, E. Y. Jiang, J. Magn. Magn. Mater. 313 (2007) 360.

29- Y. Gongqi, Y. Songliu, R. Guangming, M. Juhong, X. Xun , J. Rare Earth 25 (2007) 443. 
30- I. V. Medvedeva, T. V. Dyachkova, A. Tyutyunnik, Y. G. Zaynulin, V. V. Marchenkov, E. B. Marchenkova, K. A. Fomina, C. P. Yang, S. S. Chen, K. Baerner, Physica B 407 (2012) 159.

31- S. K. Banerjee, Phys. Lett. 12 (1964) 67.

32- V. K. Pecharsky, K. A. Gschneidner Jr., J. Appl. Phys. 86 (1999) 565.

33- T.K. Bose, R. Chahine, B.R. Gopal, M. Foldeaki, A. Barman, M. Gosh, S.K. De, S. Chatterjee, Cryogenics 38 (1998) 849.

34- J. Mira, J. Rivas, L. E. Hueso, F. Rivadulla, M. A. L.Quintela, J. Appl. Phys. 91 (2002) 8903.

35- M. H. Phan, S. C.Yu, J. Magn. Magn. Mater. 308 (2007) 325.

36- S. Pal, E. Bose, B. K. Chaudhuri, H. D. Yang, S. Neeleshwar, Y. Y. Chen J. Magn. Magn. Mater. 293 (2005) 872.

37- J. Yang, Y. P. Sun, W. H. Song, Y. P. Lee, J. Appl. Phys. 100 (2006) 123701.

38- A. Asamitsu, Y. Moritomo, Y. Tokura, Phy. Rev. B 53 (1996) 2952.

39- L. Zhu, H. S. Yang, J. Liu, Y. S. Chai, P. H. Li, X. H. Chen, L. Z. Cao, Phys. Lett. A 336 (2005) 76.

40- N. F. Mott, E. A. Davis. Electronics Process in Non Crystalline Materials, Second ed., Clarendon Press, Oxford, 1979.

41- $\quad$ K. Sega, Y. Kuroda, H. Sakata, J. Mater. Sci. 33 (1998) 1303.

42- $\quad$ P. Mandal, Phy. Rev. B. 61 (2000) 14675.

43- B. H. Kim, J. S. Kim, T.H. Park, D. S. Le, Park Y W, J. Appl. Phys. 103 (2008) 113717. 
Table 1: XRD crystallite size (P), average SEM grains size (G) and $T_{c}$ of $\operatorname{La}_{0.7} \operatorname{Sr}_{0.3} \mathrm{Mn}_{1-\mathrm{x}} \mathrm{Ni}_{\mathrm{x}} \mathrm{O}_{3}$ composites.

\begin{tabular}{lrcc}
\hline $\mathrm{x}$ & Symmetry & $\mathrm{P}(\mathrm{nm})$ & $\mathrm{G}(\mu \mathrm{m})$ \\
\hline 0.025 & Rhombohedral & 20.9 & 0.537 \\
0.05 & Rhombohedral & 19.57 & 0.482 \\
0.075 & Orthorombic & 16.85 & 0.414 \\
0.1 & Orthorombic & 16.34 & 0.382 \\
0.125 & Orthorombic & 14.24 & 0.302 \\
\hline
\end{tabular}


Table 2: Magnetic and magnetocaloric parameters for $\mathrm{La}_{0.7} \mathrm{Sr}_{0.3} \mathrm{Mn}_{1-\mathrm{x}} \mathrm{Ni}_{\mathrm{x}} \mathrm{O}_{3}$ composites

\begin{tabular}{cccc}
\hline $\mathbf{x}$ & $\mathbf{T}_{\mathbf{c}}(\mathbf{K})$ & $\boldsymbol{\delta} \mathbf{T}_{\mathbf{F W H M}}(\mathbf{K})$ & $\mathbf{R C P}(\mathbf{J} / \mathbf{k g})$ \\
\hline 0.025 & 310 & 109 & 88 \\
0.05 & 287 & - & - \\
0.075 & 256 & 130 & 105 \\
0.1 & 229 & - & - \\
0.125 & 180 & 66 & 47 \\
\hline
\end{tabular}


Table 3: $\mathrm{S}_{0}, \mathrm{~S}_{1}, \mathrm{~S}_{3 / 2}, \mathrm{~S}_{3}$ and $\mathrm{S}_{4}$ components in TEP below $\mathrm{T}_{\mathrm{s}}, T^{*}(K)$ and $\mathrm{E}_{\mathrm{s}}(\mathrm{mev})$.

\begin{tabular}{rccccccc}
\hline $\mathrm{x}$ & $\mathbf{S}_{\mathbf{0}}$ & $\mathbf{S}_{\mathbf{1}}$ & $\mathbf{S}_{\mathbf{3} / 2}$ & $\mathbf{S}_{\mathbf{3}}$ & $\mathbf{S}_{\mathbf{4}}$ & $T^{*}(K)$ & $\mathrm{E}_{\mathrm{s}}(\mathrm{mev})$ \\
\hline & & & & & & & \\
0.025 & 18.092 & -0.334 & -0.499 & 0.25 & $-1.31 \times 10^{-7}$ & 243 & 138 \\
0.05 & 28.788 & -0.48755 & -0.499 & 0.25 & $-1.47 \times 10^{-7}$ & 213 & 369 \\
0.075 & 14.860 & -0.20017 & -0.499 & 0.25 & $-2.14 \times 10^{-8}$ & 233 & 509 \\
0.1 & - & - & - & - & - & - & 680 \\
0.125 & - & - & - & - & - & - & 144 \\
\hline
\end{tabular}




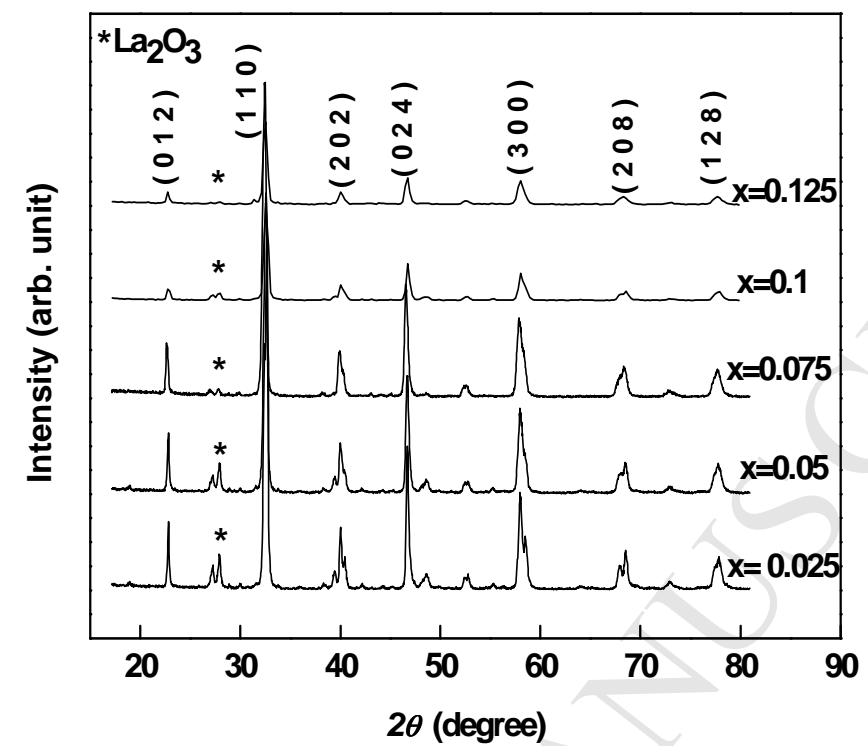

Fig. 1: Room temperature XRD patterns for $\mathrm{La}_{0.7} \mathrm{Sr}_{0.3} \mathrm{Mn}_{1-\mathrm{x}} \mathrm{Ni}_{\mathrm{x}} \mathrm{O}_{3}$ composites. 


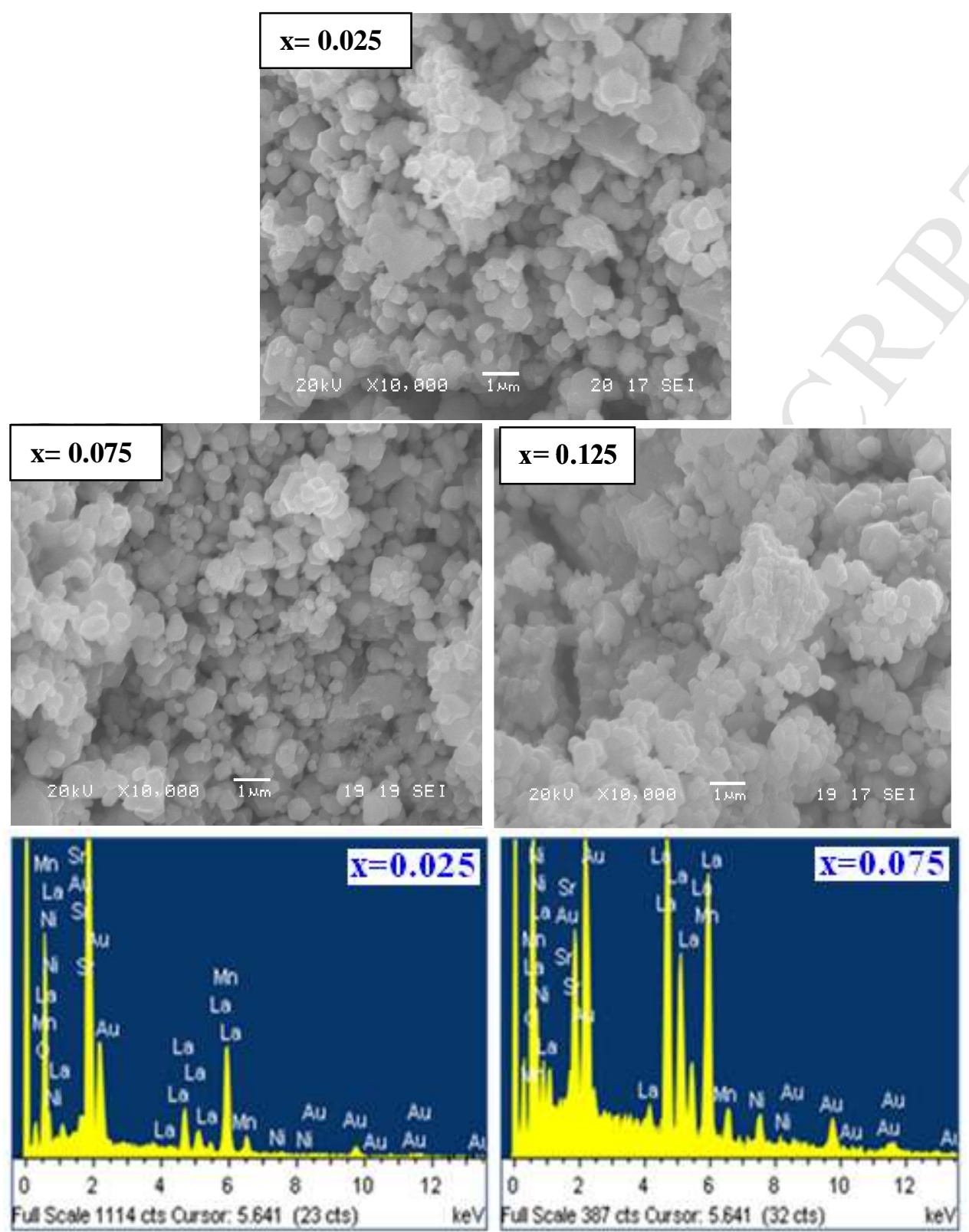

Fig. 2: SEM micrographs and EDX for $\mathrm{x}=0.025,0.075,0.125$ composites. 


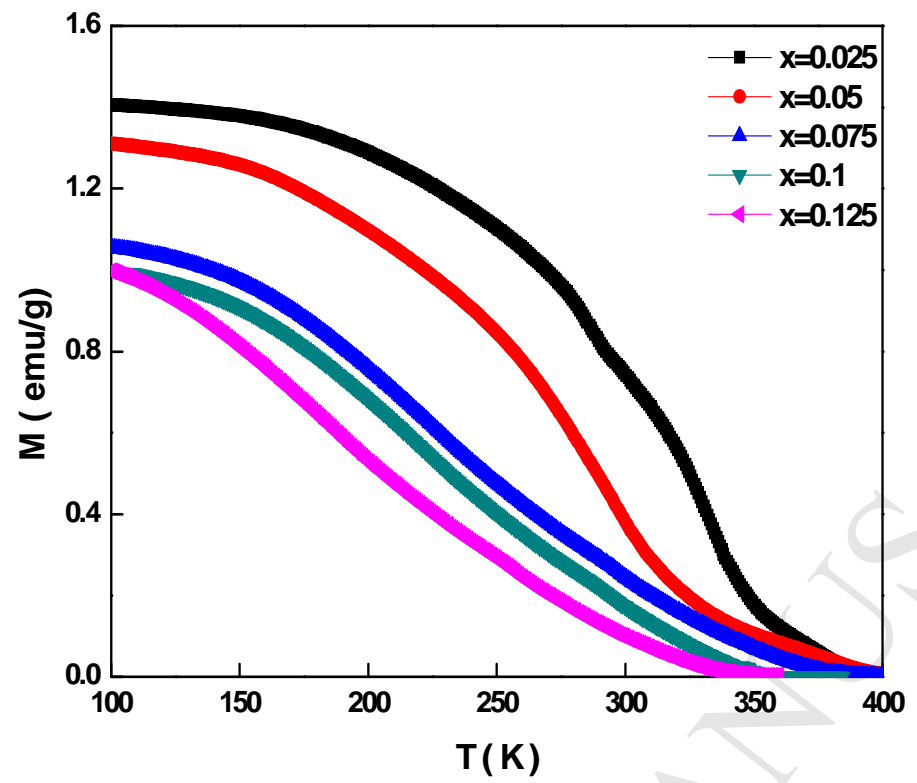

Fig. 3: The temperature dependent magnetization at $\mathrm{H}=100$ Oe for $\mathrm{La}_{0.7} \mathrm{Sr}_{0.3} \mathrm{Mn}_{1-\mathrm{x}} \mathrm{Ni}_{\mathrm{x}} \mathrm{O}_{3}$ composites. 

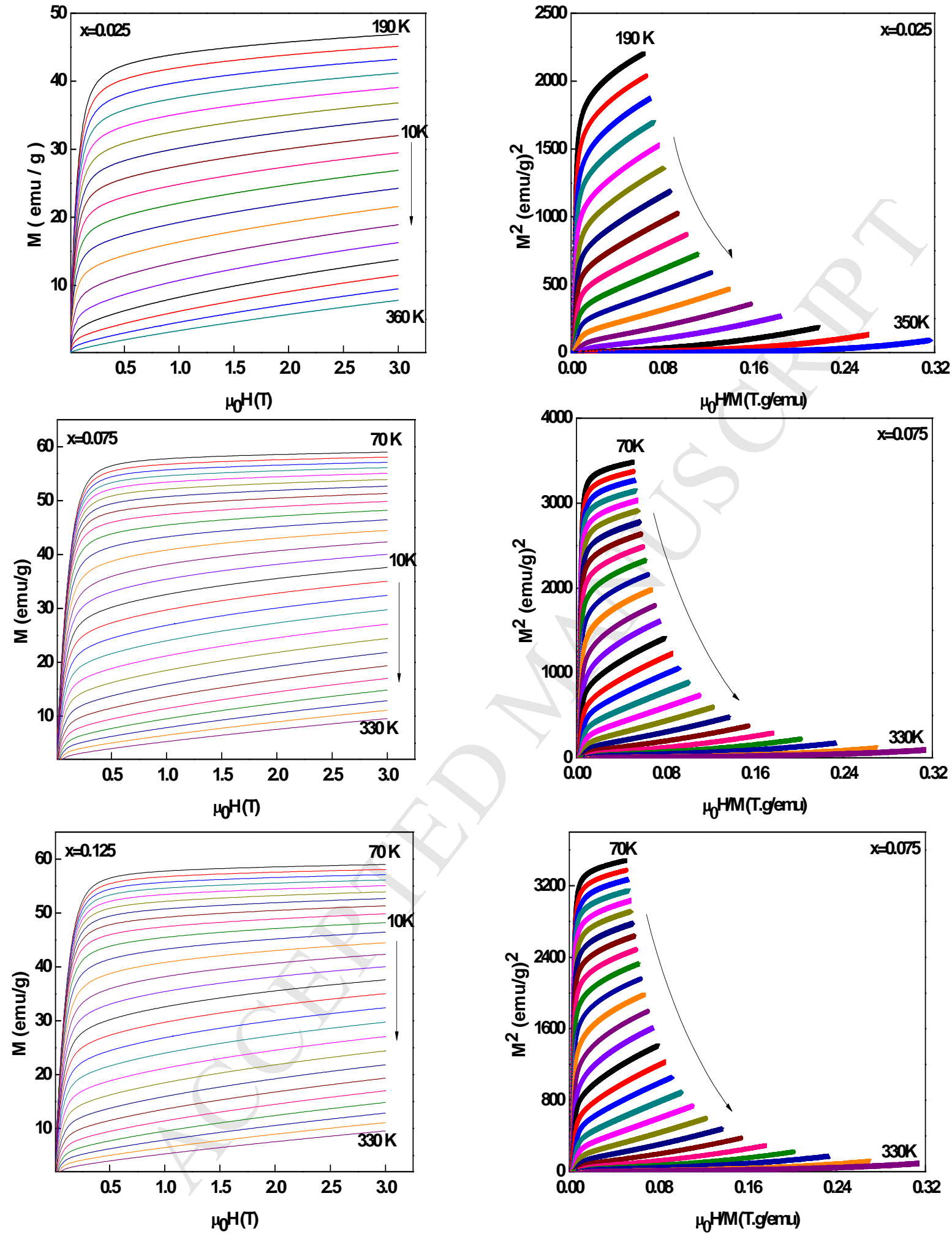

Fig. 4: The isothermal magnetization curves (M vs $\mu_{0} H$ ) and Arrott plots ( $M^{2}$ vs $H / m$ ) for $x=0.025, x=0.075$ and $x=0.125$ composites. 


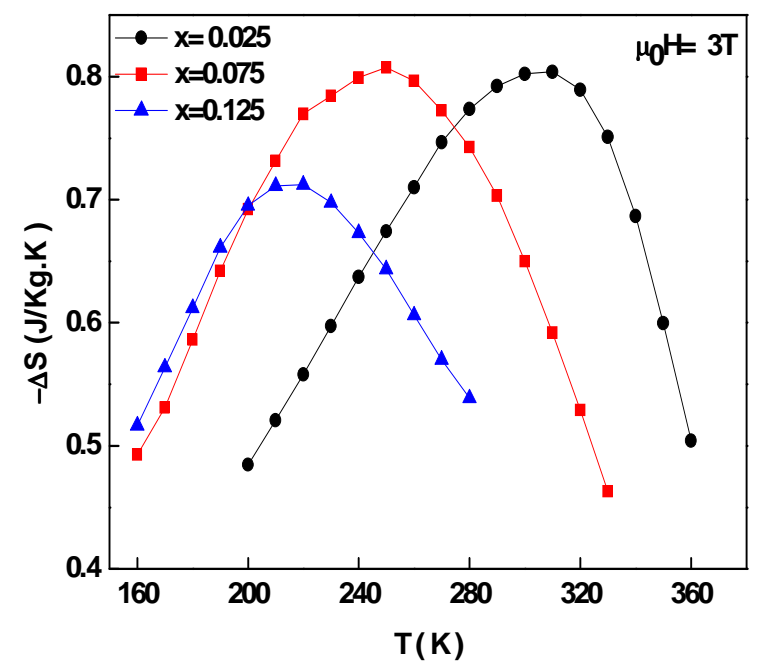

Fig. 5: Thermal variation of $\Delta S$ for $x=0.025, x=0.075$ and $x=0.125$ composites. 

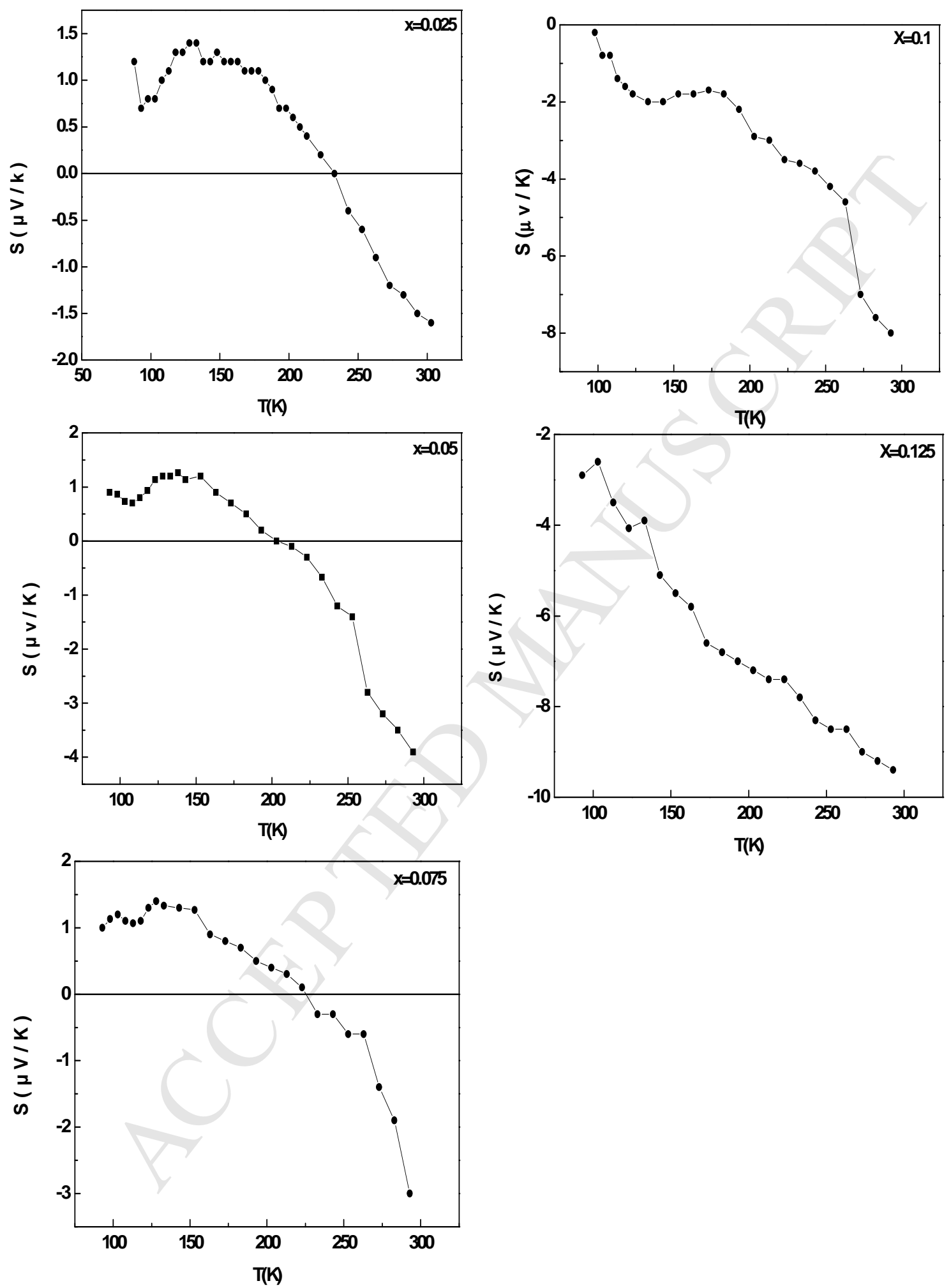

Fig. 6: The temperature dependence of Seebeck coefficient for $\mathrm{La}_{0.7} \mathrm{Sr}_{0.3} \mathrm{Mn}_{1-\mathrm{x}} \mathrm{Ni}_{\mathrm{x}} \mathrm{O}_{3}$ composites. 

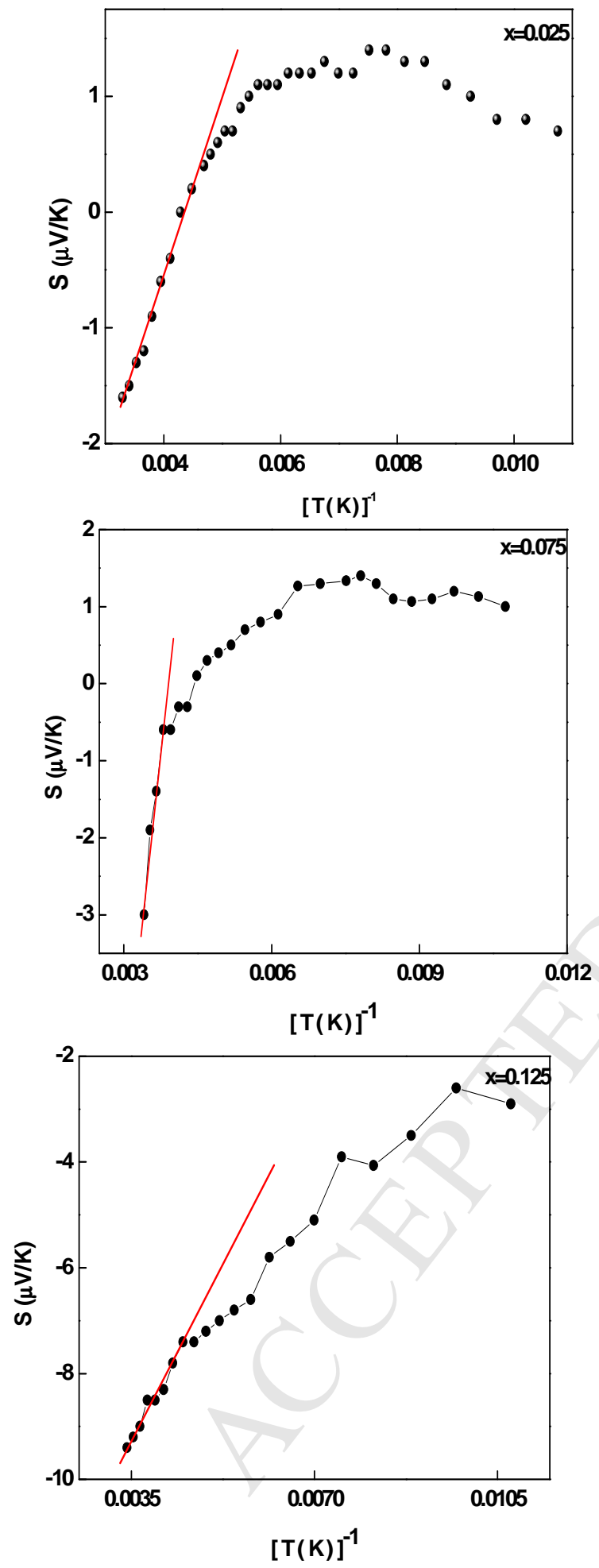

Fig. 7: The best fitting of Mott equation with TEP data at high temperatures for $x=0.025$, $0.075,0.125$ composites. 


\section{Highlights}

The most important points in the manuscript:

- Structural, magnetic and magnetocaloric properties of $\mathrm{La}_{0.7} \mathrm{Sr}_{0.3} \mathrm{Mn}_{1-\mathrm{x}} \mathrm{Ni}_{\mathrm{x}} \mathrm{O}_{3}$ have been investigated.

- $\mathrm{Ni}^{2+}$ doping results in structural transformation.

- The magnetic properties are suppressed with $\mathrm{Ni}^{2+}$ addition.

- $\mathrm{x}=0.075$ composite shows the highest RCP value of $105 \mathrm{~J} / \mathrm{kg}$.

- In thermoelectric measurements, $\mathrm{Ni}^{2+}$ doping decreases hole conduction. 